\title{
STUDIES BY THE BARANY ROTATION AND CALORIC TESTS OF TUMORS OF THE NERVUS ACUSTICUS.*
}

\author{
Drr. Harris H. Vail, Cincinnati, Ohio.
}

In this report I wish to record the findings in ten cases of verified tumor of the eighth nerve by the Barany rotation and caloric tests.* I desire to express my gratitude to Dr. Cushing for the opportunity of studying these cases in his clinic. Cases No. 1, 2, 3, 4 have been fully reported by Dr. Cushing in his volume on tumors of the nervus acusticus, ${ }^{1}$ these cases being cases XXVI, XXVII, XXVIII and XXIX in his monograph. The remaining six cases have been studied subsequent to the writing of the monograph.

I feel my limitations in writing upon this subject, but in the desire to establish the position of the Barany tests, I report my observations in the hope that others may report corresponding findings in order that the clinical status of these tests may become more clearly defined.

I. H. Jones ${ }^{2}$ in his volume on Equilibrium and Vertigo reports examinations by the rotation and caloric tests on a series of pathological cases, among them seven cases of probable tumor of the nervus acusticus.

Ernest C. Grey ${ }^{3}$ studied nine cases of cerebello-pontile new growths by the caloric test.

I shall now take up these ten cases of tumor of the eighth nerve, giving them in the order of their examination, with a brief resumé of their history and clinical findings, the report of the Barany tests as recorded by me on their charts, the operative findings by Dr. Cushing, and in a few cases the post-operative Barany Test findings.

Case 1. Mrs. R. A. D., 29, P. B. B. H., Surg. No. 5,712.

Complaint and History. Headaches, diplopia, failing vision, twitching of left side of face and sudden deafness in left ear. No tinnitus. Onset three years ago with twitching in face and deafness. Progress steady. Bilateral choked discs. Palsy of the leit external rectus muscle. Nystagmus, ataxia, deafness left ear.

Barany Test. November 13, 1916.

Spontaneous Nystagmus. Very slow and in slight excursions when looking to the left, right eye having horizontal jerks while left eye has a peculiar slow rotary motion. When looking to the right, the excursions are more rapid but not so rapid as those produced

\footnotetext{
*From the Surgical Clinic of the Peter Bent Brigham Hospital,
} 
later by the rotation. The nystagmus is a mixture of horizontal and rotary. When looking upwards there is present a definite rotary nystagmus, excursions of good amplitude. No nystagmus when looking forwards or downwards.

Pointing Reactions. Right shoulder, elbow and leg normal. Left shoulder shows at times an inward deviation which is not constant.

Rotation. Head $30^{\circ}$ forwards. To the right-brisk horizontal after-nystagmus to left shared slightly. and to slight excursions by the left eye (left abducens palsy present). Duration, ten seconds. Past pointing-definite deviation of both arms, right 4 inches to the right; left 1 inch to the right.

To the left-brisk horizontal after-nystagmus to the right equal in both eyes. Duration, ten seconds. Past pointing-very slight deviation of left arm to the left. No deviation of right arm. Both membrana tympani are slightly retracted, otherwise normal.

Hearing. Right ear acute. Left ear nil. Weber referred to right ear.

Caloric Tests. Water, $68^{\circ} \mathrm{F}$. Right ear-head $30^{\circ}$ forward. Rotary nystagmus to left in one minute. Past pointing--outward deviation of right arm; no deviation of left. No dizziness or nausea.

Left ear-head $30^{\circ}$ forwards. No nystagmus after five minutes. No past pointing. No dizziness or nausea.

Operation. November 23, 1916, Dr. Harvey Cushing. "Exposure of small left acoustic tumor with fragmentary intra-capsular removal. At operation the nerve consisted of the core of a tumor which evidently projected into or up to the canal in the customary fashion. Nerve incised and a small bit of tumor was projecting into cerebellum high up and anterior and almost out of reach. This was not removed."

Post-operative Barany Rotation and Caloric Tests. December 15, 1916.

Spontaneous Nystagmus. To right there is a moderately brisk horizontal nystagmus shared equally by both eyes. To left a horizontal with slight rotary tendency in both eyes, slower when looking to the left than when looking to the right. Straight ahead--none. Upwards-very slight rotary and vertical nystagmus in both eyes. Downwards-none.

Extra-ocular Muscles. Palsy of left external rectus. Axis of vision. Right eye normal. Left-inwards and slightly downwards.

Spontaneous Past Pointing. Right-none. Lreft-inward deviation of 2 inches on first trial; on subsequent trials done without deviation. 
Rotation. Head $30^{\circ}$ forward. To right-fairly rapid horizontal after-nystagmus of very weak amplitude. Quick component to left. Duration, ten seconds.

To left-slight rotary nystagmus of very questionable quality, to right. Duration, ten seconds. Past pointing on right rotation right -3 inches to right. Left-touches. Past pointing on left rotation-touches with both arms.

Examination of Ears. There is slight retraction of both M. T.

Hearing. A. D. Watch, 3 feet; Whispering Voice, 8 feet + ; Rinné, 512 fork 15-10; Weber to right.; A. S. Watch, 0 ; Whispering Vnice, 0 ; Rinné, 0 . Loud yelling not heard.

Caloric. Water $68^{\circ} \mathrm{F}$. Head $30^{\circ}$ forwards. Right ear-rotary after-nystagmus to left in one minute, 30 seconds.

Case 2. T. S. R., 39, P. B. B. H., Surg. No. 5,921.

Admitted December 18, 1916. Complaint. Failing vision, deafness, tinnitus on left, diplopia, nausea, drowsiness, numbness left side of face. Onset one year ago. Fundi show bilateral choked discs measuring $6 \mathrm{D}$. Right abducens palsy; left is distinctly weakened.

Barany Rotation and Caloric Tests. December 22, 1916.

Spontaneous Nystagmus. A nystagmoid condition when looking to the left. None when looking to the right, upwards, downwards or straight ahead.

Extra-ocular Muscles. Weakness of both external recti muscles, most marked on right.

Pointing Tests. Touches normally on both sides.

Rotation. Head $30^{\circ}$ forwards. To right-no after-nystagmus whatever. Past pointing-right arm 8 inches deviation to right, touching in twenty-five seconds. Left arm 2 inches deviation to right.

To left--no after-nystagmus whatever. Past pointing-left arm to left 3 inches; touching in eighteen seconds. Right arm to left 2 inches. Subjectively no nausea or dizziness.

Ears. Both membrana tympani retracted, especially left.

Hearing. A. D. Watch, 1 foot; Whispering Voice, 10 feet + ; Rinné. 34-1\%, with 512 fork; Galton, 0.7; Weber to right. A. S. Watch, 0; Whispering Voice, 0; Rinné, 0: Galton and Weber not heard.

Patient to all tests absolutely deaf.

Caloric Tests. Water $65^{\circ} \mathrm{F}$. Head $30^{\circ}$ forward. Right earno nystagmus after four minutes. No past pointing, vertigo or nausea. 
Left ear-no nystagmus after seven minutes. No past pointing, vertigo or nausea.

Operation. December 26, 1916, Dr. Cusling.

A tumor of the left acoustic nerve about 1 inch in diameter was removed within the capsule. Right recess not explored.

Post-operative Barany Rotation and Caloric Tests. January 19, $191 \%$, twenty-four days after operation.

Hcaring. Right ear as before. Left ear-Watch, 0 ; Whispering Voice, 0 ; Loud Conversation, 1 foot; Galton, 0.2 ; Low Limit, 1,024. This test made with continuous irrigation of opposite ear.

Rotation. Head $30^{\circ}$ forward. To right-no after-nystagmus. No past pointing. No nausea or dizziness.

To left-no after-nystagmus. No past pointing. No nausea or dizziness.

Caloric Test. Head $30^{\circ}$ forward. Water $65^{\circ} \mathrm{F}$. Right earrotary nystagmus after two minutes. Past pointing-right arm 2 inches to right. Left arm 2 inches to right. Patient vomited in four minutes.

Left ear-rotary nystagmus to right in four minutes with slight dizziness. No past pointing.

Letter of January 1, 1919. Patient reports herself blind but otherwise perfectly well.

Casc 3. Mrs. F. L. S., 30, P. B. B. H., Surg. No. 981.

Admitted March 3, 1914.

History. Headache, nausea and vomiting, thirteen months. Failing vision, four months. Ataxia, eight months. Dizziness, eight months. Paresthesia right side of face, nose and tongue, three months. Impairment of hearing on left, three years. Tinnitus, left, three years. Fundi show marked choked discs with secondary atrophy. $6 \mathrm{D}$. swelling

March 5, 1914. Caloric test by Dr. Ernest Grey. Right ear irrigated cold; moderately good nystagmus. No nausea or dizziness. No reaction movements. Left ear irrigated cold; very slight nystagmus. Right arm touched; left arm shows deviation of $6 \mathrm{~cm}$. to left.

Right ear cold, left ear hot; moderately good nystagmus, slight nausea and dizziness. Slight deviation of left arm to left, varying $2-6 \mathrm{~cm}$. Right arm once touched, several times deviated to right $4 \mathrm{~cm}$.

Ear Examination. Membrana tympani normal.

Operation. March 12, 1914, Dr. Cushing. Exploration of both lateral recesses negative April 5, 1914-no tinnitus, hearing as before. Readmitted May 2, 1914; patient in same condition. 
Operation. May 5, 1\%14, Dr. Cushing. No tumor seen or felt in left cerebellar hemisphere. I'atient discharged May $: 3,1 ! 1]$, with presumptive diagnosis (unverified) of left aconstic neuroma. Readmitted January 2, 1!17, P. B. B. H., Surg. No. (i,1):;. Hearing unchanged. Tinnitus--none. Ataxia present.

Barany Rotation and Caloric Tests. January :3, 191\%.

- Spontaneous Mystagmus. lirisk, horizontal nystagmus to both sides shared equally by both eyes. Jerks are of very short amplitude and about equal to either side. Upward-a slow vertical and rotary nystagmus which does not persist. At times when looking straight ahead there is present a slow rotary nystagmus lasting .i-6 jerks. Dow'nward-none.

E.rtra-ocular Muscles. Axis of vision of right eye slightly upward and inward. Left eye straight ahead.

Past Pointing. Touches with both arms.

Rotation. Head $30^{\circ}$ forward. To right-after-nystagmus horizontal to left. Duration, twelve seconds. No past pointing.

To left-after-nystagmus horizontal to right. Duration, seven seconds.

Ears. Both membrana tympani normal.

Hiaring. A. S. nil. A. D. Watch, is feet: Whispering Voice, 12 feet + ; Rinné, 58-16; Galton, normal; Weber to right ear. (Tested with continuous irrigation of opposite ear.)

Caloric Test. Water $52^{\circ} \mathrm{F}$. Head $30^{\circ}$ forward. Right eargood rotary after-nystagmus in fifty-two seconds. No error or cleviation on past pointing tests.

Left ear-no after-nystagmus after six and one-half minutes. No error or deviation on past pointing tests.

Opcration. January 22, 191\%, Dr. Cushing. Partial intra-capsular enucleation of a left acoustic neuroma. No post-operative tests made.

Case t. Mr. A. E. L., 40, P. B. B. H., Surg. No. 6,0!8.

Admitted January $16,191 \%$, with history of gradual loss of vision of right eye, headache, staggering gait, fainting spells; duration, three years. Left ear has been "poor" all his life and he has been hard of hearing for as long as he can remember. Two years ago noticed left ear was getting very deaf. Never any tinnitus. Bilateral choked disc with swelling 2-3 D., extreme atrophy of nerve heads and chorioretinitis in left eye.

Barany Tests. January 24, $191 \%$.

Spontancous Nystagmus. None upward or ahead; when looking to right there is a horizontal nystagmus, very poorly sustained and of small amplitude; speed rather rapid. When looking to left there 
is a brisk horizontal nystagmus very well sustained. Eye muscles show slight weakness of left external rectus.

Spontaneous Past Pointing. Right constant inward deviation of 1 inch; left-none.

Rotation. Head $30^{\circ}$ forward. 'To right-horizontal after-nystagmus lasting thirty seconds.

Past Pointing. No deviation, no nausea or vomiting.

To left-horizontal after-nystagmus lasting eighteen seconds.

Past Pointing. No deviation, no nausea or vomiting.

Ears. Cerumen in left canal, when removed both $M$. T. are pale, glistening, very much retracted, especially left.

Hearing (with continuous irrigation of ear not tested). A. D. Watch, 4 feet; Whispering Voice, 8 feet + ; Conversation, 18 feet + ; Loud, normal ; Galton, normal ; Low Limit, 128; Rinné, 60-25.

A. S. Watch, 0; Whispering Voice, 0, 2 inches; Conversation, 3 feet; Loud Yelling, normal; Low Limit, 1,024.

Caloric Test. $60^{\circ} \mathrm{F}$. Right ear-no nystagmus after five minutes. No dizziness. No past pointing.

Left ear-no nystagmus after eight minutes. No dizziness. No past pointing.

Operation. January 26, 191\%, Dr. Cushing.

Intra-capsular enucleation of left acoustic tumor. Post-operative Barany tests not done.

Case 5. Mrs. C. M., P. B. B. H., Surg. No. 6,32\%.

Admitted February 26, $191 \%$.

History. Pain began in right ear four years ago like sawing machine with deafness; for the past four to five months there has been a buzzing in left ear like a bee; headaches for four years. Failing vision for ten months; four months ago almost completely blind on right; the tinnitus appeared three to four months prior to onset of deafness. Has choked disc 4-5 D. bilateral.

Barany Tests. March 2, 191\%.

Spontaneous Nystagmus. To right, marked horizontal nystagmus-amplitude and speed greater than when looking to right. Upwards-small rotary vertical nystagmus. Downward--none. Straight ahead-none. Eye muscles normal.

Spontaneous Past Pointing. Touches normally right and left.

Rotation. Head $30^{\circ}$ forward. To right-horizontal after-nystagmus; good amplitude, duration, eighteen seconds. To left-horizontal after-nystagmus; good amplitude, duration, twenty-four seconds. No past pointing in either test.

Ears. Both M. T. normal. 
Hearing. A. D. Watch, 0; Whispering Voice, 0 ; Spoken Voice, 3 feet ; Low Limit, 1,024; Galton, 0.4 ; Rinné. A. S. Watch, 2 feet ; Whispering Voice, 10 feet; Spoken Voice, normal ; Low Limit, 128 ; Galton, 0.1 ; Rinné, 40-20 seconds; Weber to left ear.

Caloric. Water $64^{\circ} \mathrm{F}$. Right ear-no nystagmus after five minutes. No past pointing. Tests done with head $30^{\circ}$ forwards, $60^{\circ}$ backward, $120^{\circ}$ forward.

Left ear-rotary nystagmus after one minute, fourteen seconds. No past pointing.

Operation. March 13, 191\%. Extensive intra-capsular enucleation of right acoustic tumor, Dr. Cushing. No post-operative Barany tests done.

Case 6. Mrs. D. C., 56, P. B. B. H., Surg. No. 6,384.

History. Uncertainty of gait three years, nausea and vomiting one year, diplopia six months, failing vision several months, numbness right side of face one year, deafness right ear four years, weakness of right side of body; no pain or tinnitus; onset of gradual deafness three years ago; had vague tinnitus like crickets chirping. Bilateral choked disc, 3-4 D.

Barany Tests. March 14, $191 \%$.

Spontaneous Nystagmus. Straight ahead-slightly rotary; downward-none; upward-rotary; vertical—good amplitude. To right -slow rotary nystagmus.

Eye Muscles. Slight weakness of right external rectus.

Spontaneous Past Pointing. Touches properly with both sides. Rotation. Head $30^{\circ}$ forward. To right-horizontal nystagmus to left; duration, seventeen seconds.

Past Pointing. Right, 5 inches to right; left, 2 inches to right. Vertigo of relatively short duration.

To left-horizontal nystagmus to right; duration, thirty seconds.

Past Pointing. Left, 4 inches to left; right, 2 inches to left. Vertigo of relatively short duration.

Ears. Both canals and M. T. normal.

Hearing. A. D. Watch, 0; Whispering Voice, 0; Loudly Yelled Voice, close to ear; Rinné-Galton, 7.3. A. S. Watch, 3 feet + : Whispering Voice, 10 feet; Loudly Yelled Voice, normal; Rinné, 60-30; Galton, normal; Weber to left.

Caloric. $50^{\circ} \mathrm{F}$. Head $30^{\circ}$ forward. Right-no nystagmus after eight minutes.

Past Pointing. Right, 2 inches to right, with head $60^{\circ}$ backward, none.

Left-rotary nystagmus after thirty seconds. 
Past Pointing. Touch on both sides, with head $60^{\circ}$ backward; nystagmus became horizontal plus a rotary tendency.

Past Pointing. Left, 2 inches to left; right, 1 inch to left.

Operation. March 1ti, 191\%, Dr. Cushing. Intra-capsular enucleation of right acoustic tumor. No post-operative examination made.

Case 7. Mrs. K. G. B, 42, P B. B. H., Surg. No. 6,215.

Admitted March 29, 191\%, with history of disturbance of taste three years, deafness right ear with tinnitus (described as roaring like ocean ), numbness right side of face, headache, vomiting, ataxia. Has choked disc bilateral, $4 \mathrm{D}$.

Barany Tests. April 1, $191 \%$.

Spontancous Nystagmus. Straight ahead--there is a rotary nystagmus, fair amplitude; downward-rotary; vertical-good amplitude, slower than when looking upward. To right and left-horizontal nystagmus, good amplitude, brisker when looking to left. There is a slight rotary tendency when looking to right.

Eye Muscles. Weakness of right external rectus.

Spontaneous Past Pointing. Right-definite constant outward duration, 1-2 inches. Left-none.

Rotation. Head $30^{\circ}$ forward. To right-very brisk horizontal nystagmus to left; duration, fifteen seconds. Vertigo subjectively lasts twelve seconds.

Past Pointing. Right, 3 inches to right; left, 1 inch to right. No nausea.

To left-on stopping there is a marked slow conjugate deviation of both eyes to left lasting two seconds; then there begins a very slow horizontal after-nystagmus of extremely wide amplitude lasting three seconds. This slow nystagmus merges into spontaneous nystagmus already present.

Past Pointing. Left, touches; right, 3 inches to right.

Ears. M. T. normal.

Hearing. With irritation of opposite ear. A. D. Watch, 0; Whispering Voice, 0 ; Spoken Voice, 0 ; Loud Yelled Voice, 1 foot; Low, 2,056, not heard; Galton, 4.8; Rinné. A. S. Watch, 3 feet; Whispering Voice, 10 feet; Spoken Voice, normal; Loud Yelled Voice, normal ; Low, 128; Galton, normal ; Rinné, 56-15 ; Weber to left.

Caloric. $55^{\circ}$; head $30^{\circ}$ forward. Left ear-a slow rotary nystagmus after one minute.

Past Pointing. Left, 2 inches to left; right, 1 inch to left.

Right ear-no nystagmus after four minutes. 
Past Pointing. Right, 1 inch to right ; left, touches. Head, backward, $60^{\circ}$. No horizontal nystagmus.

Operation. April 7, 1917, Dr. Cushing. Partial intra-capsular enucleation of right acoustic tumor. Patient died in spring of 1918. No autopsy.

Case 8. Mrs. E. M. D., 41, P. B. B. H., Surg. No. 6,588.

Admitted April 11, 1917, with history of headache, deafness and tinnitus in left ear, dimness of vision. Deafness noticed about eight months ago, following a whistling tinnitus in left ear noticed two to three weeks before.

Barany Tests. April 18, $191 \%$.

Spontaneous Nystagmus. Straight ahead-none; upward-fine rotary vertical twitches; to right and left-none; downward-none. Eye muscles normal.

Spontaneous Past Pointing. Right, normal ; left, 1 inch deviation to left.

Rotation. Head $30^{\circ}$ forward. To right-horizontal after-nystagmus; brisk, good amplitude lasting fifteen seconds.

To left-horizontal after-nystagmus; brisk, good amplitude lasting fifteen seconds.

Past Pointing. Left, 8 inches to left; right, 3 inches to left. Ears. Both M. T. normal.

Hearing. A. D. Watch, 4 feet; Whispering Voice, 10 feet + ; Loud Voice, normal; Galton, 0.1 ; Low, 128; Weber to right.

A. S. Watch, 0; Whispering Voice, 1 foot ; Loud Voice, probably not heard.

Caloric. $58^{\circ} \mathrm{F}$; , head $30^{\circ}$ forward. Right-rotary nystagmus after one minute, fifty seconds. Head $60^{\circ}$ backward; nystagmus became horizontal, of good amplitude.

Past Pointing. Right, 3 inches to right; left, 1 inch to right.

Left-no nystagmus after six minutes. No past pointing. Head back; no nystagmus or past pointing.

This patient was operated on in the Johns Hopkins Hospital, May 21, 1917, and a large tumor in left cerebellar pontine fossa was found; death shortly after.

Case 9. Mr. W. D. A., 23, P. B. B. H., Surg. No. 11,724.

Admitted December 29, 1919, with history of dimness of vision left eye for a few months; deafness and tinnitus for four to five years.

Examination. Bilateral choked discs, 3-4 D. swelling with secondary atrophy. Romberg positive, tendency to fall with deviation to right on walking. Corneal reflex less active on right. Vision O. D. $20-15$; O. S. $2-200$. 
Conclusion. Right acoustic neuroma.

A right sub-temporal decompression was done January 5, 1920, by Dr. Cushing. Internal hydrocephalus found.

Barany Tests. January 22, 1920.

Spontaneous Nystagmus. To right and left-brisk horizontal nystagmus, well sustained; upward-a rotary vertical nystagmus, well sustained; looking down-none; nystagmus when looking to left has greater amplitude and less speed than when looking to the right.

Spontaneous Past Pointing. Touches on both sides.

Rotation. Head $30^{\circ}$ forward. To right-horizontal after-nystagmus to left, good amplitude; duration, fourteen seconds.

Past Pointing. Right, 6 inches to right; left, 4 inches to right.

To left-horizontal after-nystagmus to right, good amplitude; duration, ten seconds.

Past Pointing. Left, 5 inches to left; right, 3 inches to left.

Hearing. Left ear normal; right ear hears loud yelling only close to ear.

Caloric Tests. $60^{\circ} \mathrm{F}$. Right-no nystagmus after six minutes. No past pointing. Head back $60^{\circ}$; no nystagmus; no past pointing.

Left-none after three minutes; no past pointing. Head backward $60^{\circ}$; violent horizontal nystagmus; no past pointing; no vertigo.

Operation. January 25, 1920, Dr. Cushing.

Right Acoustic Neuroma. "Tumor came readily into view in right lateral recess; a bundle of nerves, $9,10,11$ were seen below tumor. It did not hug the outer side of the recess as much as usual, but lay farther over against the pons, and it is rather surprising that there were not more outspoken symptoms. Incision made through the capsule and a great mass of tumor was removed."

Post-operative. February 10, 1920, eighteen days after operation. Hearing. A. D. Watch, 0; Whispering Voice, 0 ; 512 Fork, 0 ; Galton, 1.5; Moderate Loud Conversation, 2 feet.

A. S. Watch, 2 feet; Whispering Voice, 10 feet + ; Rinné, 85-33; Galton, normal; Weber to left.

Spontaneous Nystagmus. To right-brisk horizontal nystagmus, well sustained. To left-slow horizontal nystagmus, well sustained. Upward-few rotary and vertical twitches. Downward-rotary and vertical fine twitches, well sustained. Straight ahead-none.

Spontaneous Past Pointing. Right arm points either 1 inch to right, to left or touches. Left arm-constant inward deviation of 1 inch with tendency to overshoot.

Extra-ocular Muscles. Normal. 
Rotation. Head $30^{\circ}$ forward. To right-ten turns in twentyseconds; good, brisk horizontal after-nystagmus to left; duration, twenty seconds.

Past Pointing. Right arm, 5 inches to right; left arm, 3 inches to right with overshooting.

To left-ten turns in twenty seconds; good, brisk horizontal afternystagmus to right; duration, ten seconds.

Past Pointing. Left arm, 4 inches to left ; right arm, 2 inches to left.

Caloric, Water $60^{\circ} \mathrm{F}$. Head $30^{\circ}$ forward. Right-no nystagmus after seven minutes. No past pointing. Left-rotary nystagmus after two minutes, thirty seconds. No past pointing. Head $60^{\circ}$ backward. Right - no nystagmus. No past pointing. Leftrotary nystagmus replaced by a brisk horizontal nystagmus to the right. No past pointing.

Case Io. Mr. C. R. S., 38, F. B. B. H., Surg. No. 11,861.

Admitted January 20, 1920. Marked impairment of vision, severe occipital headaches, deafness right ear four years. Bilateral choked discs, 3 D. swelling. Vision, O. D. 20-50: O. S., 20-30.

Barany Rotation and Caloric Tests. January 22, 1920.

Spontaneous Nystagmus. To the right-none; to the left-horizontal nystagmus, good amplitude, well sustained; upward-none; downward-none; straight ahead-none.

Spontaneous Past Pointing. Touches with both arms normally. Extra-ocular Muscles. Normal.

Rotation. Head $30^{\circ}$ forward. To right-wide, slow horizontal after-nystagmus to left; duration, fifteen seconds.

Past Pointing. Right arm, 12 inches to right: left arm, 4 inches to right.

To left-wide, slow horizontal nystagmus to right; duration, sixteen seconds.

Past Pointing. Left arm, 12 inches to left; right arm, 6 inches to left.

Examination of Ears. Both membrana tympani normal.

Hearing Tests. Left ear acute; right-loud conversation only heard close to ear.

Caloric Tests. Water $60^{\circ} \mathrm{F}$. Right ear-Head $30^{\circ}$ forward. No nystagmus after four minutes. No past pointing. Head $60^{\circ}$ backward. No nystagmus. No past pointing.

Left ear-Head $30^{\circ}$ forward. No nystagmus after three minutes. No past pointing. Head $60^{\circ}$ backward. A brisk horizontal nystagmus to right.

Past Pointing. Left, 1 inch to left : right, 2 inches to left. 
Operation. January 22, 1920, Dr. Cushing. Right acoustic neuroma partially removed.

Post-operative Barany Rotation and Caloric Tests. February 17, 1920 , twenty-six days after operation.

Hearing. A. D. Watch, 0; Whispering Voice, 1 inch; 512 Fork, 23-35; Galton, 2.8 .

A. S. Watch, 3 feet; Whispering Voice, 10 feet ; 512 Fork, 80-35; Galton, 0.1 ; Weber to left.

Spontaneous Nystagmus. To right-horizontal, with slight rotary tendency; good amplitude, well sustained. To left-horizontal, well sustained, good amplitude. Upward-vertical nystagmus well sustained. Downward-vertical nystagmus well sustained. Straight ahead-none.

Extra-ocular Muscles. Normal.

Spontaneous Past Pointing. Right arm, touches; left arm, deviation of 1 inch to right.

Rotation. Head $30^{\circ}$ forward. To right-good horizontal afternystagmus, brisk; duration, fourteen seconds.

Past Pointing. Right, 3 inches to right; left, 1 inch to right.

To left-good horizontal after-nystagmus, brisk; duration, thirteen seconds.

Past Pointing. Left arm, 4 inches to left; right arm, 1 inch to left.

Caloric Tests. Water $60^{\circ} \mathrm{F}$. Right ear-head $30^{\circ}$ forward. No nystagmus after four minutes, fifteen seconds.

Past Pointing. Right, touches; left, 1 inch to right.

Head $60^{\circ}$ backward. No nystagmus.

Past Pointing. Right, touches; left, 1 inch to right.

Left ear-rotary nystagmus after two minutes, forty-five seconds.

Past Pointing. Left, 3 inches to left; right, 2 inches to left.

Head $60^{\circ}$ backward. The rotary nystagmus becomes horizontal; good amplitude and speed.

Past Pointing. Left, 3 inches to left; right, 2 inches to left. SUMMARY.

Spontaneous nystagmus was present in all ten cases. It was present when looking upward in seven cases (four right-sided lesions, three left-sided). It was present when looking to one side or the other in nine cases (one case showed only a rotary vertical nystagmus on looking up).

With the right-sided lesions, the nystagmus to the left was in three cases greater than when looking to the right. In the other two cases equal to right and left. 
With the left-sided lesions, in one case nystagmus when looking to the right was greater than that when looking to the left. In one case, the nystagmus when looking to the left was greater than that when looking to the right. Two cases (one right, one left) showed only nystagmus to the left. Downward looking induced nystagmus in one case.

Spontaneous Past Pointing. Seven cases showed normal past pointing reactions. One case (left-sided) showed slight tendency to deviation inward of left arm. One case (left-sided) showed definite outward deviation of left arm. One case (right-sided) showed definite outward deviation of right arm.

Rotation Tests. After-nystagmus of proper type and in proper direction was obtained in nine cases. It was absent entirely in one case (Case 2). One case showed tendency to conjugate deviation to side opposite to lesion.

Time of After-nystagmus.

Time given in seconds

Right-sided lesion Rotation to the right-15, 14, 15, 17, 18

Five cases Rotation to the left $-16,10,3,39,24$

Left-sided lesion Rotation to the right-15, 0, 10, 12, 20

Five cases Rotation to the left $-15,0,10,7,18$

Past Pointing. Three cases showed no past pointing.

One case showed, when rotated to side opposite to lesion, inward pointing on the side of the lesion. No past pointing on other side.

One case only showed normal past pointing reactions on the two sides.

One case (Case 2) showed normal past pointing with absence of after-nystagmus. In this case the past pointing, though normal in direction, was diminished.

Normal past pointing reactions were obtained in five cases. In all of these the past pointing was normal for direction but showed decrease in distance of past pointing.

Hearing. Deafness was absolute on side of lesion in three cases. Loud voice was only heard close to ear on side affected in five cases. Conversation heard close to ear on side affected in two cases. No impairment of hearing on opposite side.

(The hearing tests were all done while continuous irrigation of opposite ear was being carried on.)

Examination of the ear drums showed normal membrana tympani in the majority of cases, remaining cases showed retraction.

Caloric Tests. In all the cases there was a failure to obtain afternystagmus with cold water from vertical canal stimulation on the side of the lesion. With stimulation of the horizontal canal (tested 
with head $60^{\circ}$ backward) in the six cases that were tested in this manner, there was a failure to produce after-nystagmus. There was an entire absence of past pointing when the ear on side of lesion was stimulated.

In four cases no after-nystagmus was obtained after stimulation of ear opposite to the side of the lesion with the head in the $30^{\circ}$ forward position. In the two cases tested with head $60^{\circ}$ back, a horizontal after-nystagmus in normal direction was obtained. In the other two cases with failure to produce after-nystagmus from stimulation of ear opposite to side of lesion with head in $30^{\circ}$ forward position, the test was not done with head $60^{\circ}$ backward. In these four cases there was an absence of past pointing reactions.

In six cases the nystagmus following irrigation of ear opposite to side of lesion appeared within one and one-half minutes. In one case in thirty seconds, in one case fifty-two seconds.

In four of these cases past pointing normal for direction but diminished in extent was present. In the other two cases no past pointing present.

\section{CONCLUSIONS.}

In ten cases of unilateral tumor of the nervus acusticus, tested by the Barany rotation and caloric tests in the manner described by I. H. Jones, ${ }^{2}$ reactions were obtained which in the great majority of the cases might be described as typical. These typical reactions are:

1. Unilateral deafness on side of lesion varying from absolute to a marked involvement.

2. Failure to obtain by the caloric test after-nystagmus and past pointing from stimulation of the labyrinth on the side of the lesion: and in some cases failure to obtain after-nystagmus and past pointing from stimulation of vertical canals of side opposite to lesion.

3. The time of the after-nystagmus obtained by rotation, as a general rule, is decreased but does not show that there is blocking of one labyrinth. Rarely there is found a halving of the after-nystagmus time when rotation to the side opposite to the lesion is done, due in my opinion to the compensation resulting from the chronicity of the lesion.

4. The past pointing tests following rotation, as a rule, do not show any reactions that might be classed as typical. The reactions are abnormal, and are probably influenced by involvment of the cerebellum through direct or indirect pressure.

5. In two cases with failure to produce nystagmus from caloric test of the unaffected side, where post-operative tests were made by 
the caloric test, they showed absence of nystagmus and past pointing reactions on the side of the lesion, with practically normal response from stimulation of the opposite side. This finding agrees with that of Eagleton, ${ }^{*}$ who recognized that increased intra-cranial pressure affected the side opposite to the lesion. In my opinion the increased pressure affected the side opposite to the lesion. In my opinion the increased pressure present in all these cases is responsible to a great extent for the irregular reactions found by the rotation tests.

6. Post-operative tests of the cochlear function of the side involved, showed an increase in its function in some of the cases.

7. Unilateral paralysis of external rectus may cause unequal: involvment of the eyes in the spontaneous nystagmus. In afternystagmus by stimulation this is a negligible factor.

8. The reactions described in the above cases are quite similar to those reported by Jones ${ }^{5}$ in Cases $26,27,28,29,30,31,32$ of his monograph.

Jones states from his experience with cerebello-pontile angle lesions it is frequently shown that the vertical semicircular canals of side opposite to the lesion fail to respond to stimulation. This has occurred with such uniformity that no symptom complex appears to be complete without it. He feels that this is due to pressure transmitted across the midline. This experience of Jones has been confirmed to some extent by my observations, though in the majority of cases response normal for type but delayed in appearance time is obtained from the contra-lateral side.

$\mathrm{Grey}^{3}$ in nine cases of cerebello-pontile tumors obtained reactions similar to the above in four cases. He found absent responses in one case and doubtful responses in one other case.

BIBLIOGRAPHY.

1. Harvey Cushing: Tumors of the Nervus Acusticus, Philadelphia, 1917.

2. I. H. Jones: Equilibrium and Vertigo, Philadelphia, 1918.

3. E. C. GraY: Studies on the Localization of Cerebellar Tumors. II-The Pointing Reaction and Caloric Test. Amer. Jour. Med. Sciences, 151, 1916, pp. 693-704.

4. W. P. Eagleton: Discussion on Paper of Dr. Isaac H. Jones. Vertigo and Barany Tests. Laryngol., Otol. and Rhinol., Section of the American Medical Association, 1917, p. 190.

5. I. H. Jones: Equilibrium and Vertigo. Philadelphia, 1918, pp. 407-435. 